\title{
Application of mesoporous silica nanoparticles for drug delivery to cancer cells
}

\author{
Bizhan Malaekeh-Nikouei (D) ${ }^{\text {, Mohammad Yahya Hanafi-Bojd (D) }}{ }^{2,3}$
}

\begin{abstract}
Cancer is one of the main causes of death worldwide. Chemotherapy is the most common method for cancer therapy which represent non-specific side effects on normal cells and tissues and drug resistance in cancer cells. There are two main mechanisms for Multi Drug Resistance (MDR) in cancer cells including: drug efflux pump and activation of anti-apoptotic pathways. Cancer chemotherapy disadvantages can be overcome by using nanoparticulate drug delivery systems like Mesoporous Silica Nanoparticles (MSNs) that have been used as drug delivery system since 2001. The present review included synthesis, targeted (active or passive) drug delivery to cancer cells, co-delivery of anticancer drugs and siRNA by MSNs and its toxicity. This review revealed that MSNs are good candidate for drug delivery to cancer cells due to its unique properties including: controllable pore and particle sizes, thermal and chemical stability, modifications of outer and inner surfaces of nanoparticles for drug and siRNA loading, attachment of ligand for targeted drug delivery, high drug loading capacity and controlled drug release, biocompatibility and biodegradation in aqueous medium.
\end{abstract}

Key Words: Cancer, Mesoporous Silica Nanoparticles (MSNs), Targeted Drug Delivery

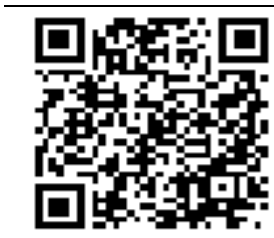

Citation: Malaekeh-Nikouei B, Hanafi-Bojd MY. [Application of mesoporous silica nanoparticles for drug delivery to cancer cells]. J Birjand Univ Med Sci. 2020; 27(3): 220-230. [Persian].

DOI http://doi.org/10.32592/JBirjandUnivMedSci.2020.27.3.101

Received: February 19, $2020 \quad$ Accepted: May 2, 2020

\footnotetext{
${ }^{1}$ Nanotechnology Research Center, Institute of Pharmaceutical Technology, Mashhad University of Medical Sciences, Mashhad, Iran

${ }^{2}$ Cellular and Molecular Research Center, Birjand University of Medical Sciences, Birjand, Iran

${ }^{3}$ Nanomedicine Department, faculty of Medicine, Birjand University of Medical Sciences, Birjand, Iran

Corresponding author; Cellular and Molecular Research Center, Birjand University of Medical Sciences, Birjand, Iran

Tel: +985632381513_Fax:+985632433004_E-mail: myhanafibojd@bums.ac.ir, my_hanafi_bojd@yahoo.com
}

r. 


\title{
كاربرد نانوذرات متخلخل سيليكا در دارورسانى به سلولهاى سرطانى
}

\author{
بيزّن ملأكه نيكويى (i)'، محمد يحيى حنفى بجد idi)
}

\begin{abstract}
جكيله

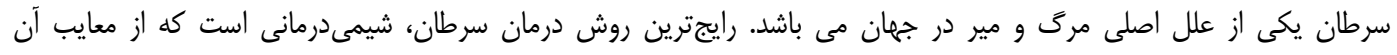

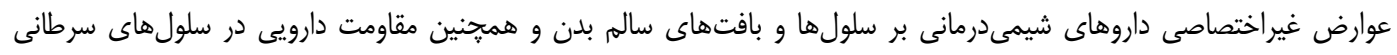

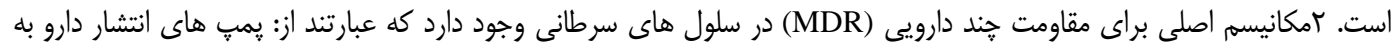

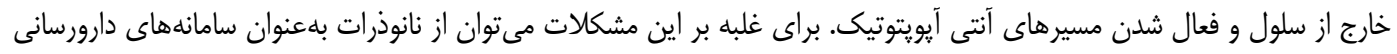

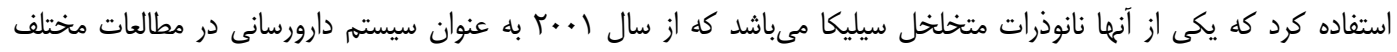

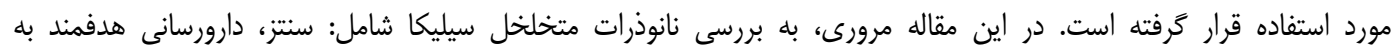

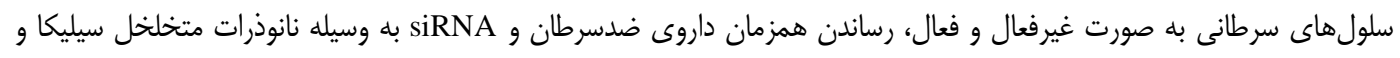

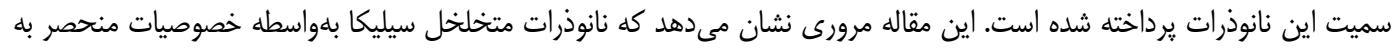

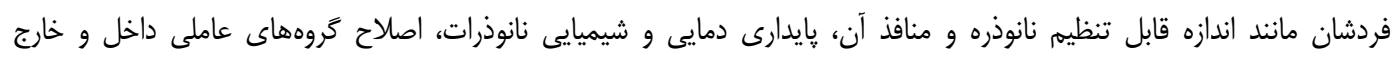

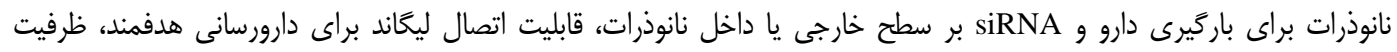

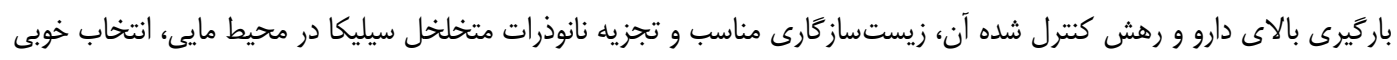

$$
\text { براى دارورسانى به سلولهاى سرطانى است. }
$$

وازههاى كليدى: سرطان، نانوذرات متخلخل سيليكا، دارورسانى هدفمند

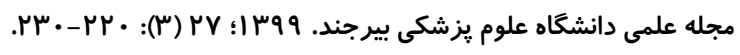

دريافت: •
\end{abstract}

' مركز تحقيقات نانوفناورى، يُوهشكده فناورى هاى نوين دارويى، دانشكاه علوم يزشكى مشهل، مشهيد، ايران

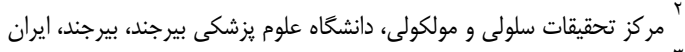

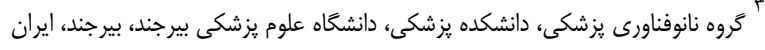

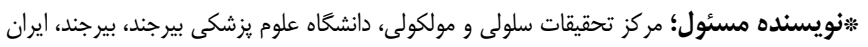

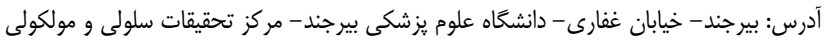

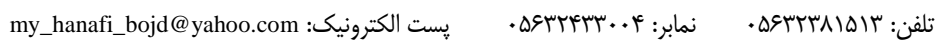


بزرگ آنها نمىتوانند از ميان اتصالات محكم بين سلولهاى

مقدمه

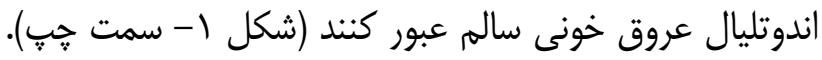
عروق خونى محل تومور، بهدليل داشتن ديوارههاى نشتئيذير،

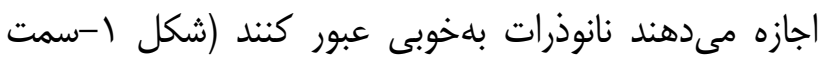

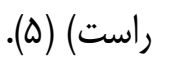

دارورسانى هدفمند به تومور بهوسيله نانوذرات، به دو دو

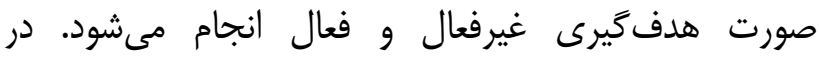

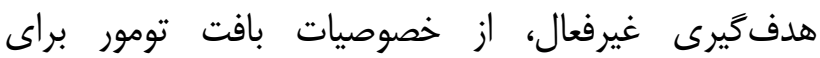

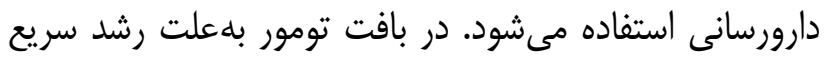

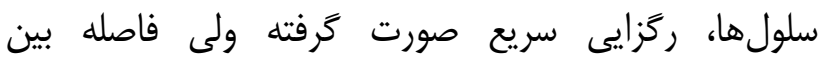

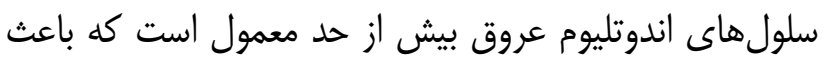

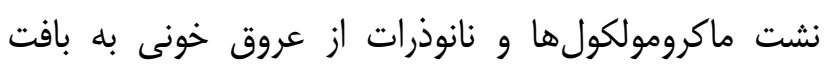
تومور مىشود. از طرفى سيستم لنفاوى بافت تومور كامل

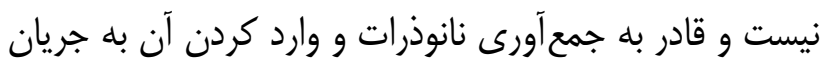

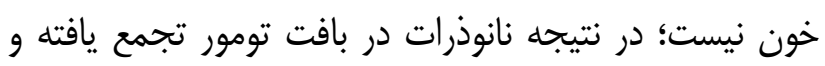

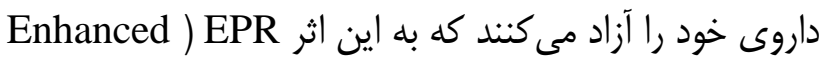
(Permeability and Retention

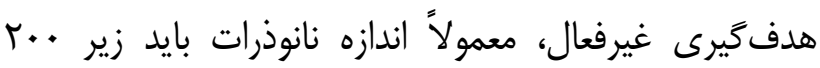

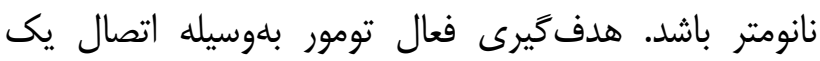

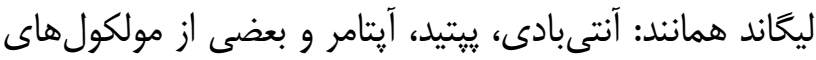

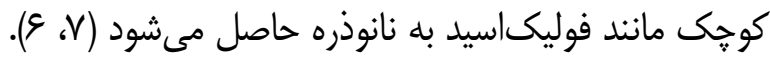

سرطان، يكى از علل اصلى مرك و مير است كه با رشد

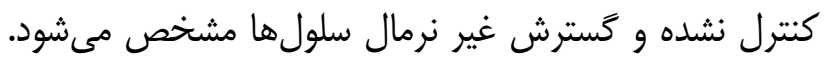
سرطان ناشى از عوامل خارجى همانند: دخانيات و مواد مواد

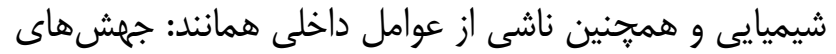

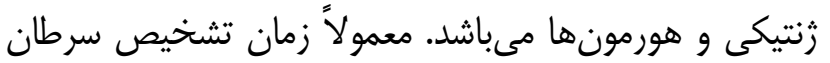

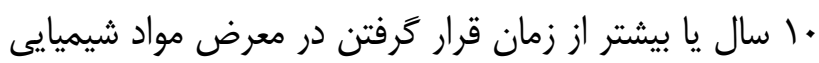

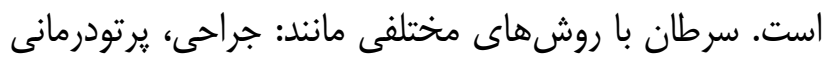

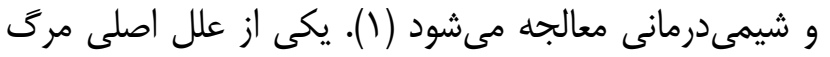

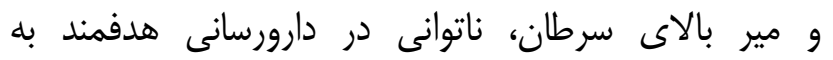

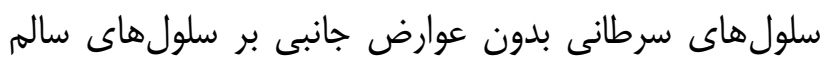
است. به نظر مىرسد نانوتكنولوزى بتواند در حل اين بران مشكل راهخشاى خوبى باشد. خصوصيات منحصر به فرد نانوذرات مانند اندازه ذرات، نسبت سطح به حجم بالا، توانايى هدفَيرى آنها، توان

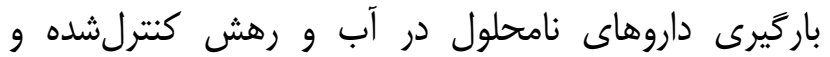

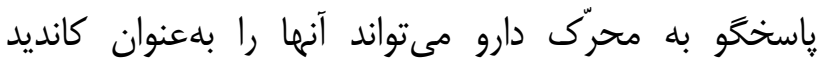

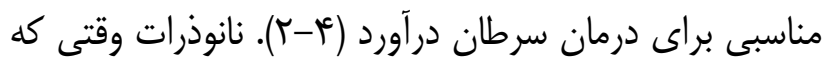

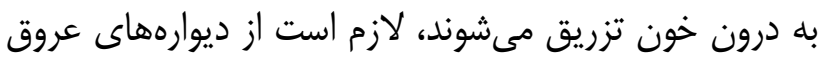

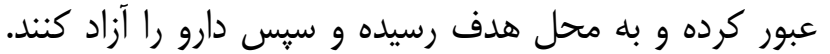
برخلاف مولكولهاى كوجى، نانوذرات بهدليل اندازه بهنسبت

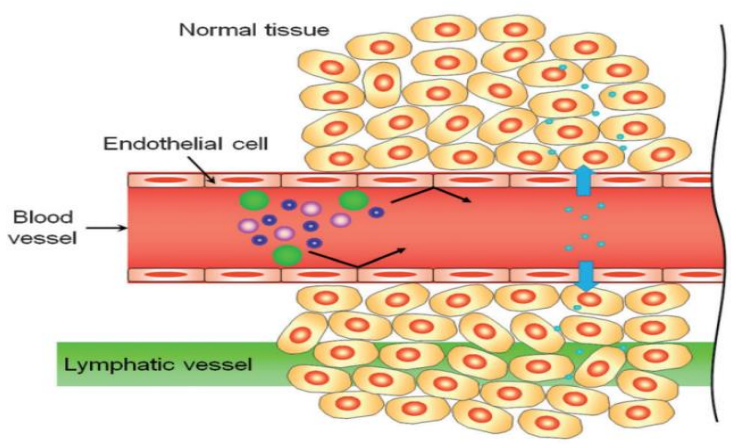

- $\bigcirc$ nanoparticles

- small molecule

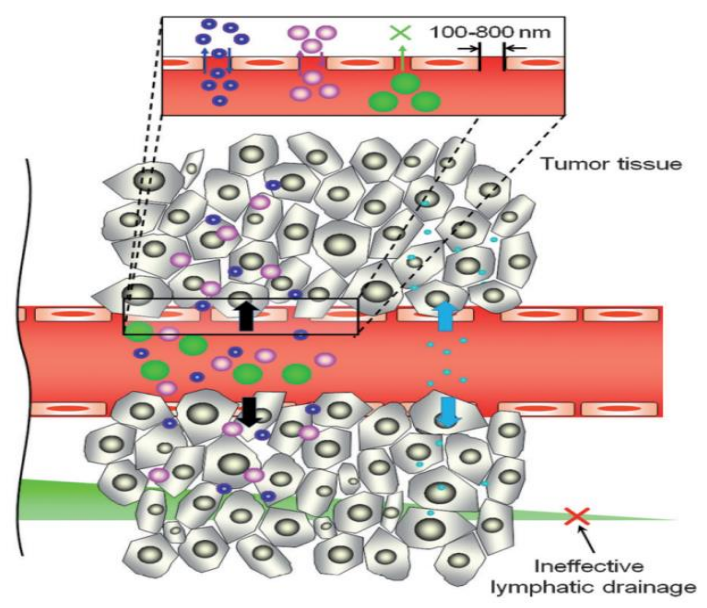

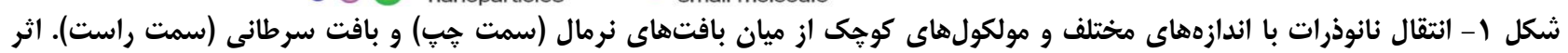

EPR 
محلول سورفكتانت اضافه كرده تا شبكه سيليكا بر روى

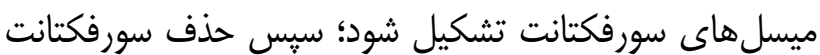

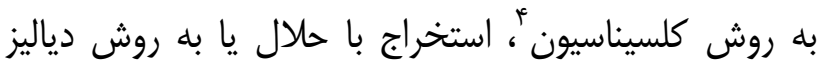

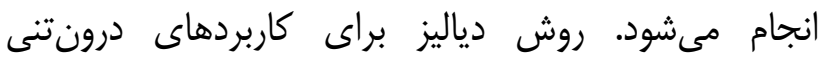

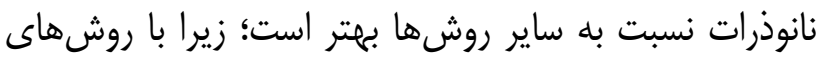

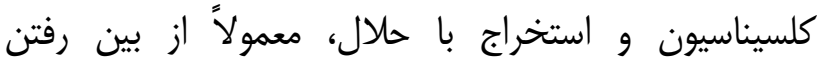
كروههاى عاملى سطحى و افزايش اندازه نانوذرات را خواهيه

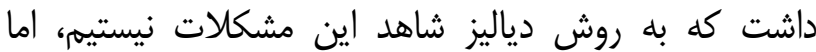

روش دياليز گران و زمانبر مىباشد (سا، بان (I).

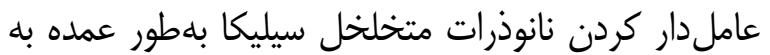

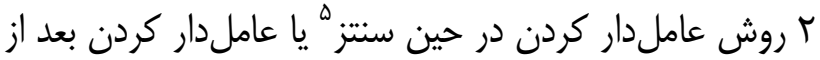

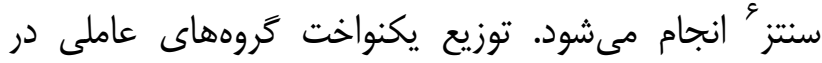
سطح داخلى و خارجى نانوذرات و عدم انسداد منافذ نانوذرات، از مزاياى روش عاملدار كردن در حين سنتز است. عاملدار

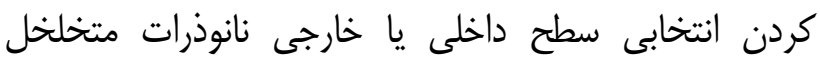

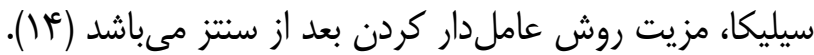

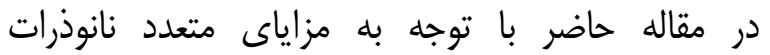

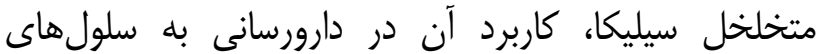
سرطانى مورد بررسى قرار گرفته است.

\section{هنانوذرات متخلخل سيليكا به عنوان حامل داروهاى}

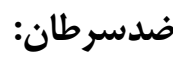

در مطالعات متعددى، نانوذرات متخلخل سيليكا بهعنوان

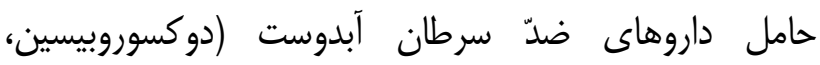

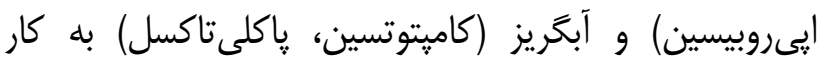

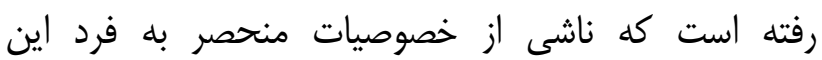

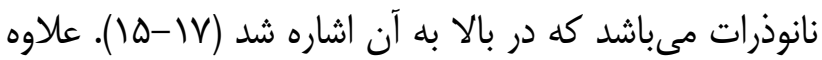

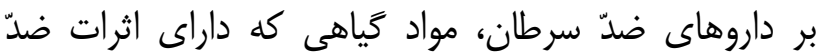

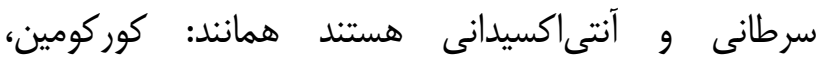
كوئرستين و كاليك اسيد در نانوذرات متخلخل سيليكا

\section{Calcination}

5 Co-condensation

6 Grafting
تاكنون از نانوذرات مختلفى براى درمان سرطان استفاده

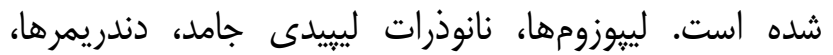

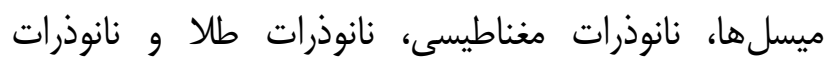
متخلخل سيليكا به اين منظور استفاده شده است (9، 1).

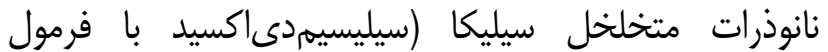
شيميايى SiO2)، مواد جامدى هستند كه داراى ساختار متخلخل شبيه لانه زنبور عسل با صدها كانال خالى بوده و

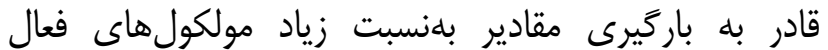
زيستى هستند. اين نانوذرات، خصوصيات منحصر به فردى مانى

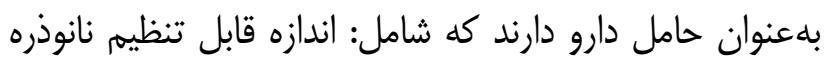
و منافذ آن، پيايدارى دمايى و وارو شيميايى نانوذرات، اصلاح كروههاى عاملى سطح داخل و خارج نانوذرات، قابليت اتصال

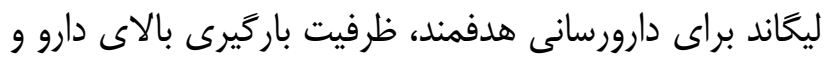

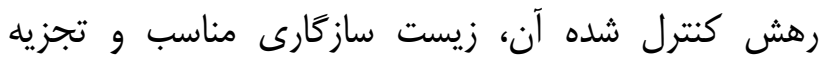

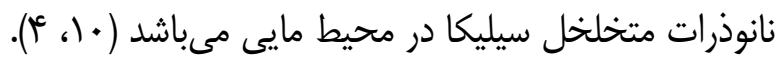

\section{سنتز و عامل دار كردن نانوذرات متخلخل سيليكا}

سنتز نانوذرات متخلخل سيليكا براى اولينبار در سال r199 انجام شد (1). براى سنتز اين نانوذرات، عا جزء اصلى مورد نياز است كه عبارتند از:

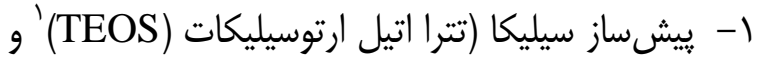

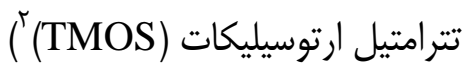

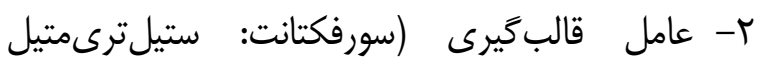

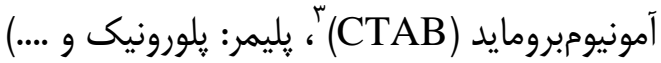

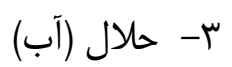

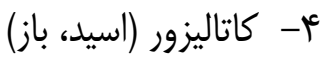

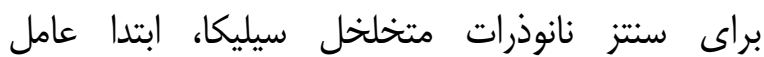
قالبگيرى را كه معمولاً سورفكتانت مىباشد با مضور كاتاليزور در حلال حل كرده و سيس ييشساز سيليكا را به 
فولات انجام شود. نتايج آزمون سميت سلولى و اثرات ضدّ

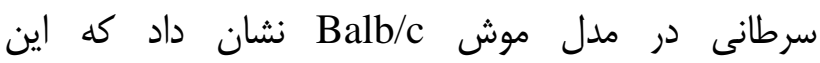
فرمولاسيون سميت بيشترى نسبت به داروى آزاد بر روى درى درى دادي سلولهاى سرطانى در مطالعه برونتنى و درونتنى دارد (•r).

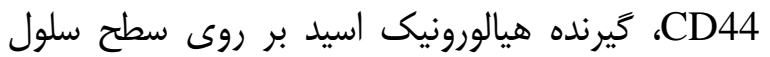
است كه بر روى سلولهاى إيىتليال، هماتويوئتيك و و سلولهاى عصبى با مقدار كم بيان مىشود و در بسيارى از ازئ

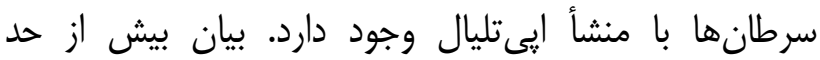

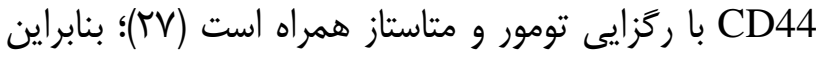

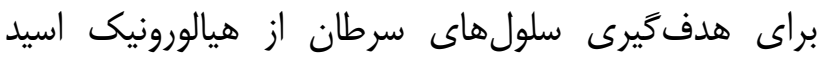

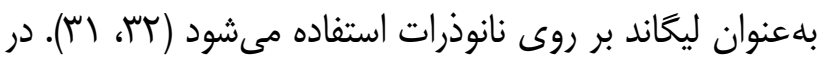
يثزوهش Palanikumar و همكاران، نانوذرات متخلخل سيليكا سنتز شد و داروى ضدّ سرطان دوكسوروبيسين در آن آن

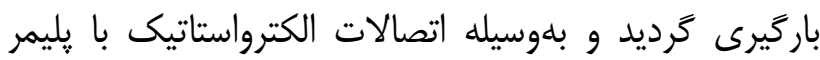
PEG-PDS-NH2 با استفاده از ييوند آميدى به يليمر سطح سيليكا متصل شد.

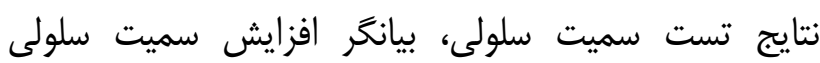

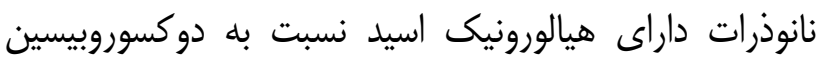
آزاد بر روى سلولهاى داراى اين گيرنده (HeLa) بود (بس).

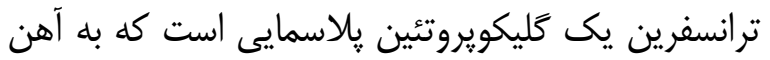

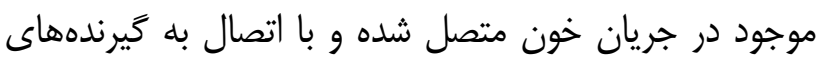

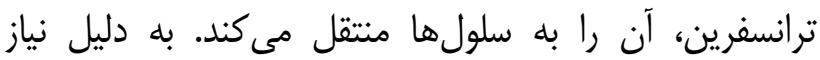

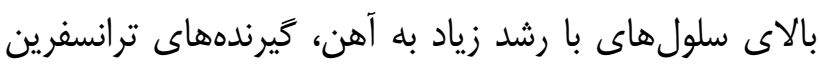

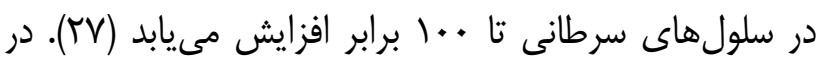

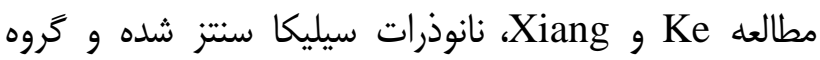

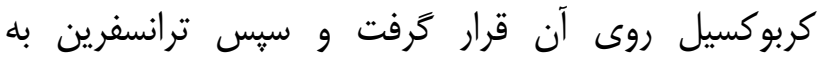
نانوذرات متصل و داروى سورافنيب درون نانوذئ فرات

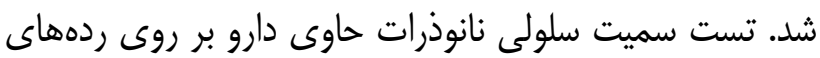
سلولى سرطان تيروئيد مقاوم (res-TPC-1, res-BCPAP) كه بيان بالاى كيرنده ترانسفرين داشتند انجام شد كهائ كأن

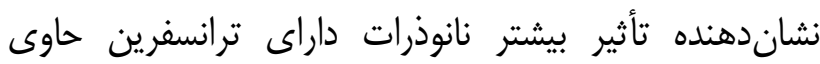
سورافنيب نسبت به نانوذرات فاقد ترانسفرين و همجنين دارين

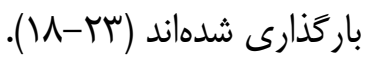

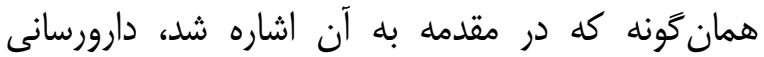

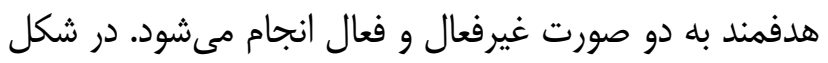

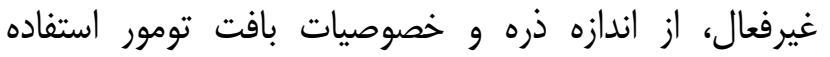
مىشود و تجمع دارو در ناحيه تومور اتفاق مى افتند. در

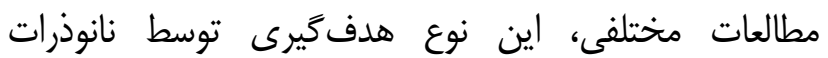
متخلخل سيليكا انجام شده است (هآ، ع بآ). هدفَيرى فعال تومورها توسط نانوذرات بهدليل سميّت كمتر براى ساير بافتها و اثرات اختصاصىتر، مورد توجه قرار

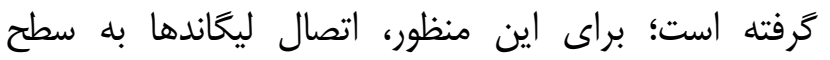

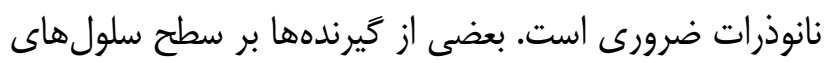

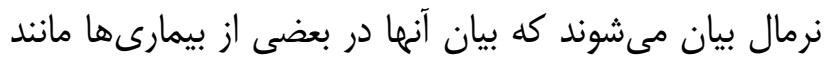

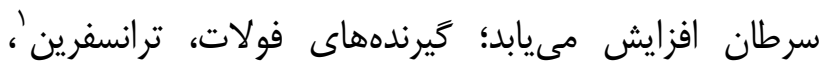

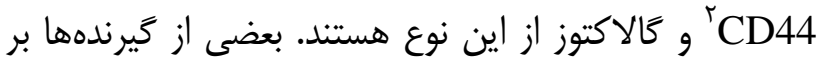

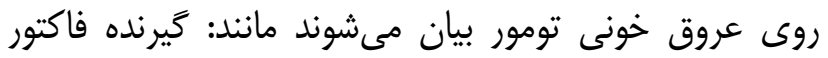

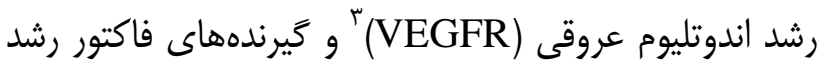

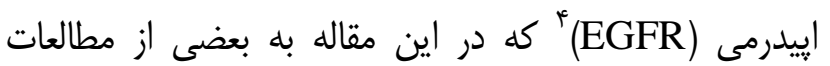

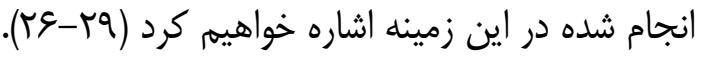

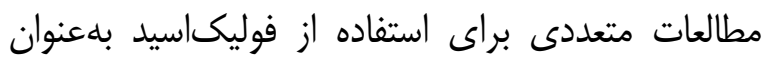
يك ليكاند بر روى نانوذرات متخلخل سيليكا انجام شده است كه بهعلت عدم وجود كيرنده فولات بر روى بافتهاى سالم و و

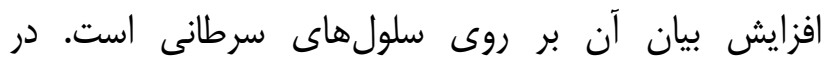

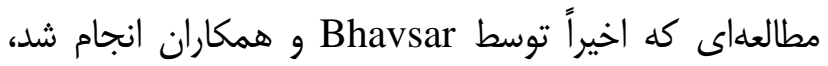
ابتدا نانوذرات متخلخل سيليكا سنتز شده و با آمينويروييلترى إنتر اتوكسى سيلان (APTES) و و سبس بات سوكسينيك انيدريد واكنش داده شده است تا نانوذرات متخلخل سيليكا با كروها كربوكسيل حاصل شود. داروى آناستروزول در اين نانوذات اندرات

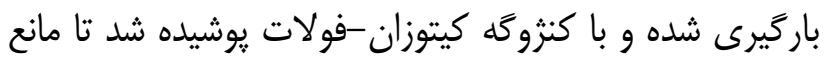
رهش زودهنكام دارو شده و همجنين دارورسانى هدفمند با بات

\footnotetext{
${ }^{1}$ Transferrin

${ }^{2}$ Cluster of differentiation 44

${ }^{3}$ Vascular Endothelial Growth Factor Receptor

${ }^{4}$ Epidermal Growth Factor Receptors

5 3-Aminopropyltriethoxysilane
} 
زيستسازكار، زيستتجزيهيذير و غير ايمونوزن باشد و بتواند با محافظت از siRNA در مقابل نوكلئازهاى سرم، آن را به يه بافت هدف برساند؛ همجنين اين سيستم بايد بتواند پِ از از

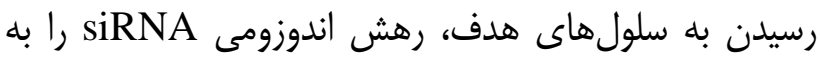
سيتويلاسم افزايش دهد. از نانوذرات مختلفى همانند: يليمرها (يلىاتيلن ايمين، كيتوزان و ....)، نانوذرات ليييدى (لييوزوم)،

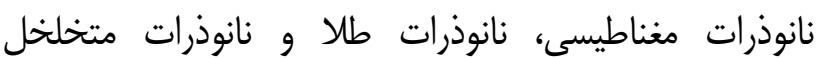

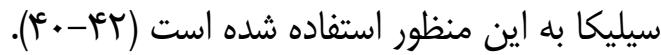
نانوذرات متخلخل سيليكا علاوه بر مزاياى ذكر شده در

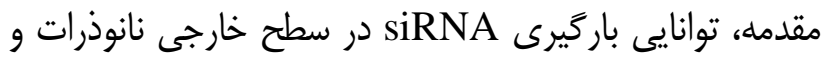

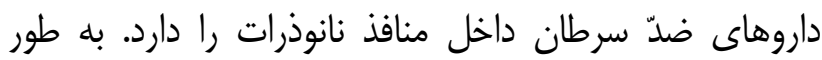

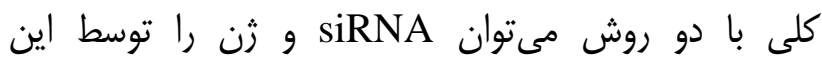

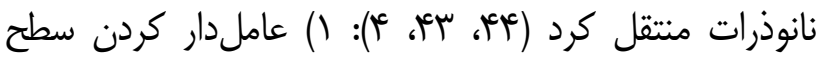

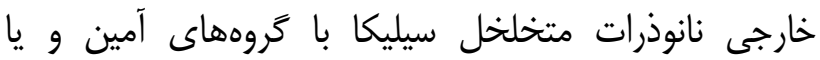

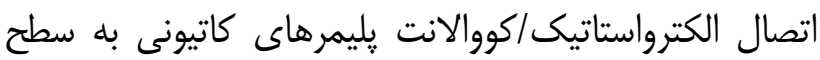
خارجى نانوذرات براى بارگيرى siRNA بر سطح خارجى لئى نانوذرات و r) قرار گرفتن siRNA يا ثن داخل منات منافذ اين

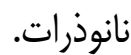
اخيراً براى افزايش كارآيى داروهاى ضدّ سرطان، رساندن همزمان دارو و siRNA توسط نانوذرات متخلخل سيليكا به اريه سلولهاى سرطانى انجام مىشود. در يكى از اولين مطالعات

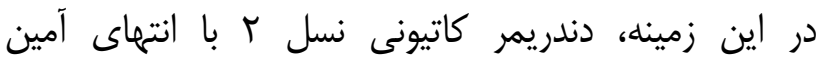
(G2 PAMAM) سيليكا متصل شد تا باركيرى siRNA داشته و همجنين از سماز رهش زودهنگًام دوكسوروبيسين محبوس درون نانئ نانوذرات

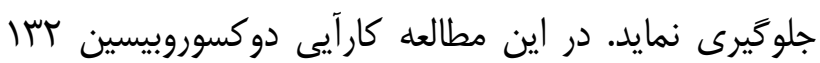
برابر افزايش يافت (شكل شماره r) (هأ).
داروى آزاد بود. مطالعات درونتنى در موشهاى حاوى تومور،

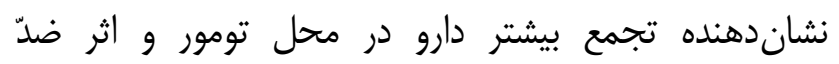
سرطانى بهتر نسبت به نانوذرات فاقد ترانسفرين بود (عسا).

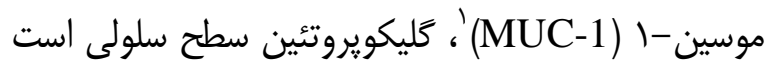

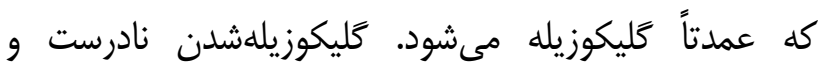

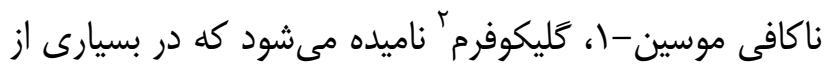
سلولهاى سرطانى ايىتليال مانند: سرطان سينه، كولولن،

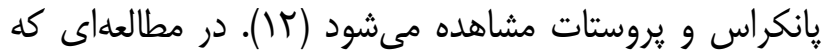
توسط گروه ما انجام شد نانوذرات سيليكا داراى گروه تيول

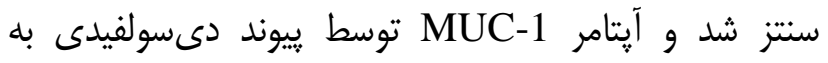

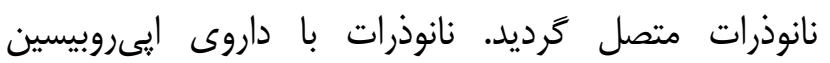
بارگيرى شد و برداشت سلولى نانوذرات و سميت سلولى برد برد روى رده سلولى سرطان سينه (MCF-7) انجام گرديد (ها؟).

\section{هنانوذرات سيليكا بهعنوان حامل دارو و siRNA:} RNA مداخله با 19 -سM نوكلئيك اسيد است كه باعث خاموش كردن زن در در

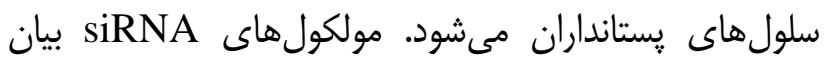

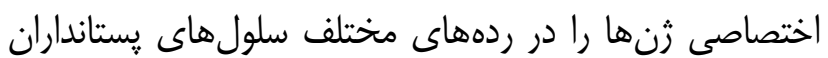

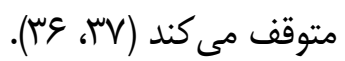

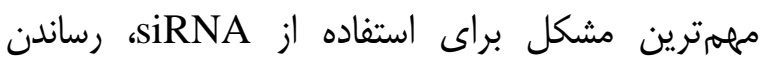
كارآمد و بىخطر آن به سلولهاى هدف است. خصوصين آنسئ

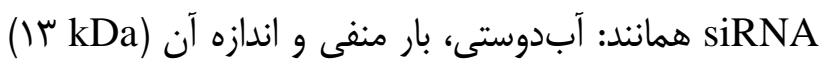

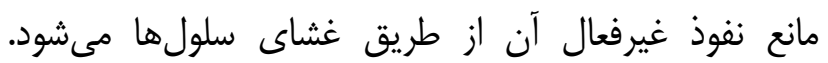

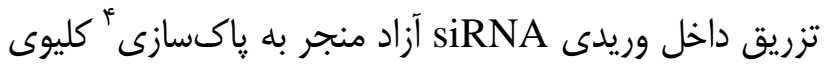

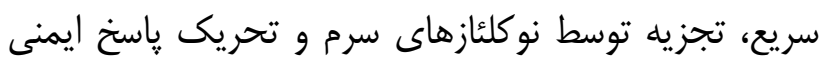

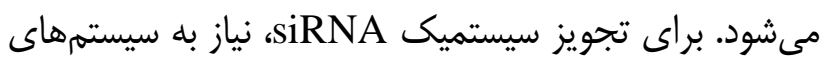
دارورسانى جديد است تا بتوان بر مشكلات فوق غلبن بردين كرد

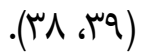

سيستمهاى بهينه براى انتقال سيستماتيك siRNA بايد

1 mucin-1

2 mucin-1 (MUC-1) glycoform

3 small interfering RNA

4 Clearance 

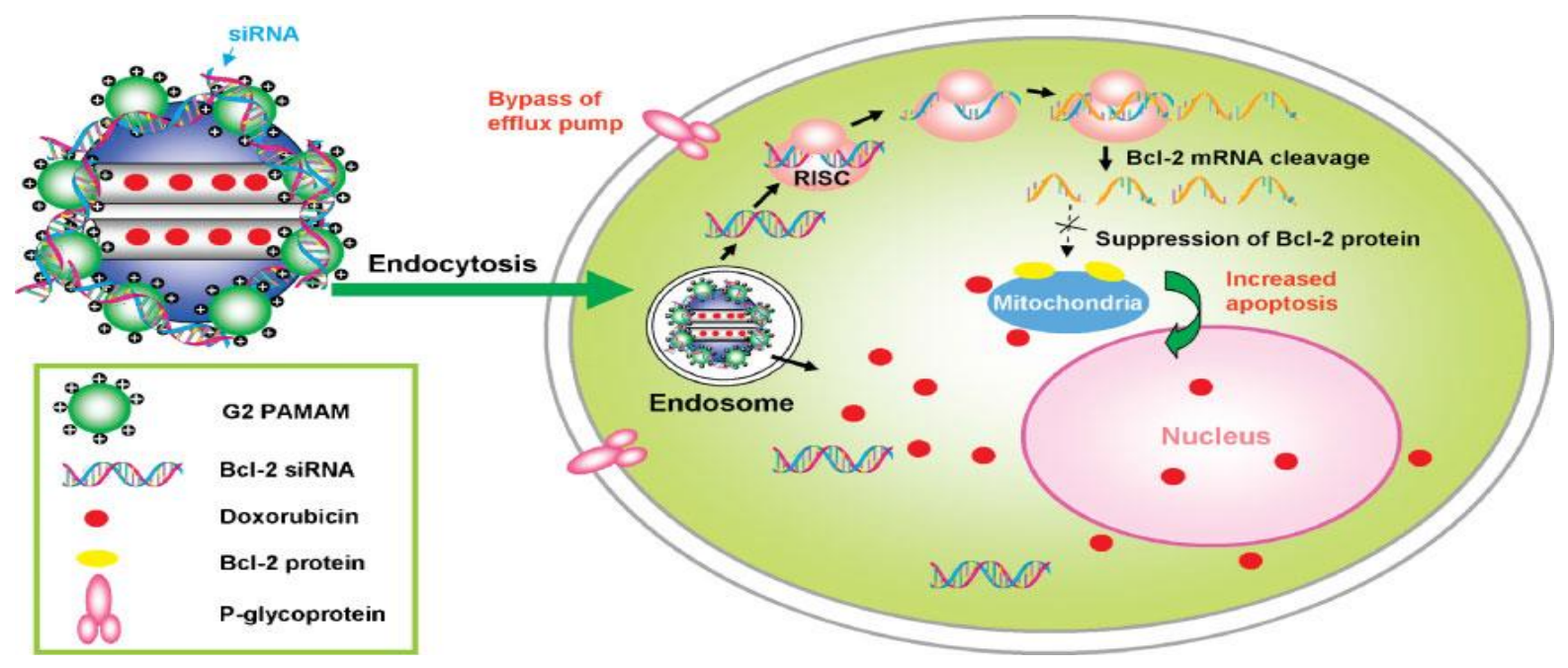

شكل r- رساندن همزمان دارو و siRNA توسط نانوذرات متخلخل سيليكا به درون سلول (fQ)

كارسينوما بلهطور معنى دارى افزايش داد (FV).

\section{لزيست ساز كارى و سميت نانوذرات متخلخل سيليكا:}

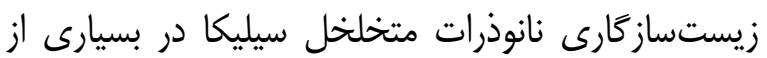

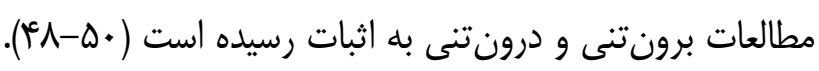

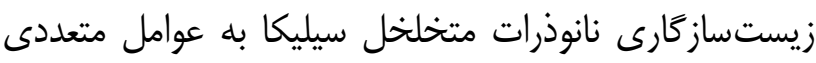
همجون: دوز نانوذره، شكل و خصوصيات سطحى نانوذرات، ساختار متخلخل و اندازه نانوذرات بستخى دارد (هات (ه). به طور

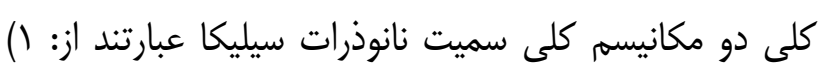

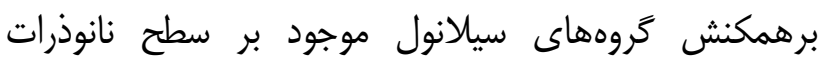

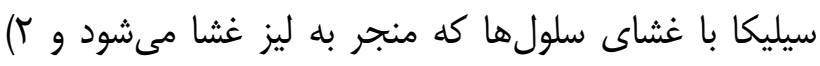

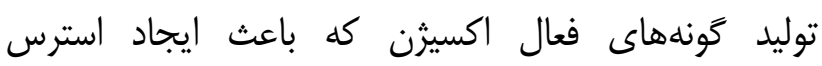
اكسيداتيو و در نهايت القاى آيويتوز مى شود كائ.

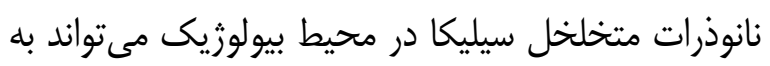

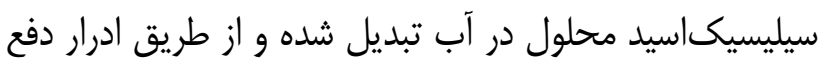

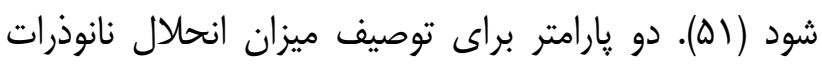
متخلخل سيليكا ضرورى است: خصوصيات فيزيكوشيميايى

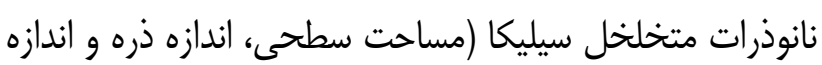

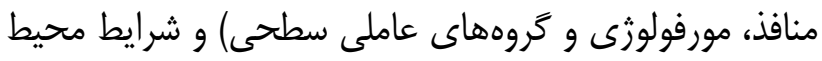
تجزيه (pH)، دما و غلظت)(· •).
در يزوهشى كه در سال •. • انجام شده از نانوذرات

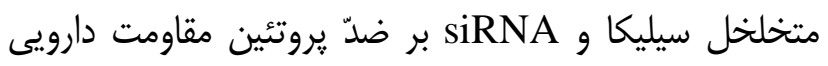

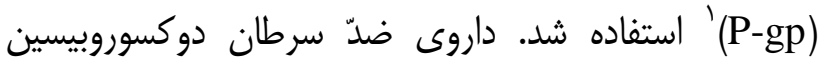

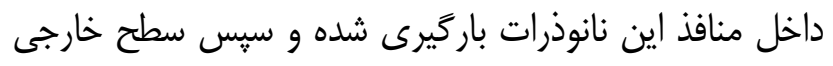

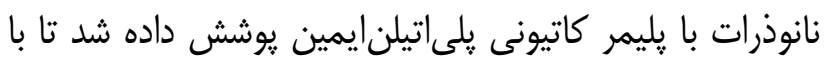

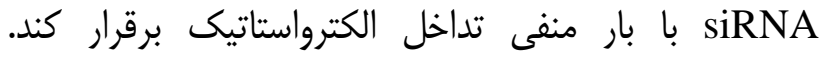

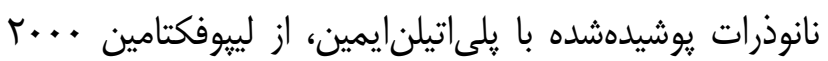

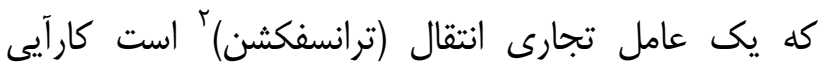

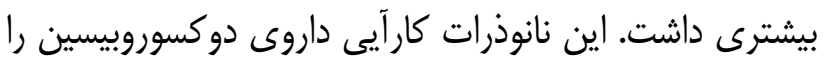

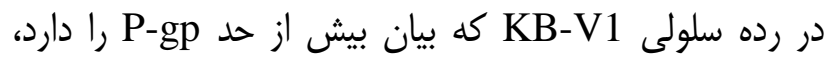
بلبطور معنى دارى افزايش داد (ع) كان).

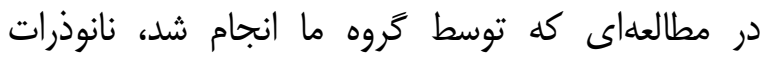

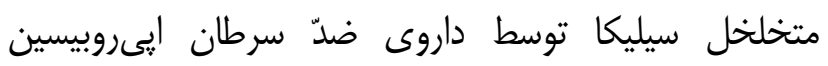

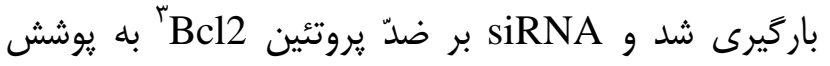

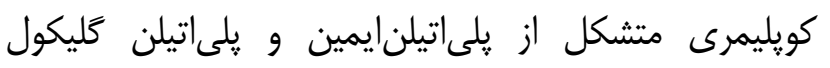

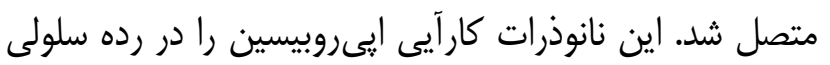
كولون كارسينوما (C26) و در مدل موشى إنى داراى كولون

\footnotetext{
${ }^{1} P$-gylycoprotein

${ }^{2}$ Transfection

${ }^{3}$ B-cell lymphoma 2
} 
نانوذرات نياز به تحقيق بيشتر براى ورود به بازار دارد.

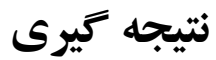

\section{تقدير و تشكر}

درمانهاى رايج سرطان، عوارض زيادى شامل: مقاومت

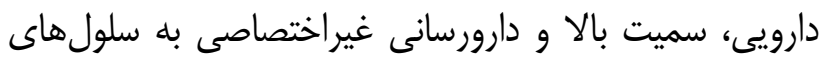

از همكارى معاونت محترم تحقيقات و فناورى و مركز

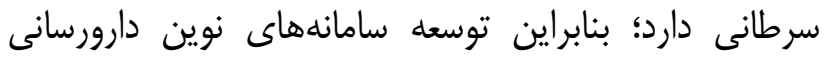

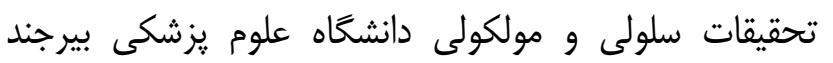

مورد نياز است. نانوذرات متخلخل سيليكا بهدليل داشتن وارين

$$
\text { قدردانى مى كردد. }
$$

خصوصيات منحصر به فرد، مىتواند در اين زمينه مورد

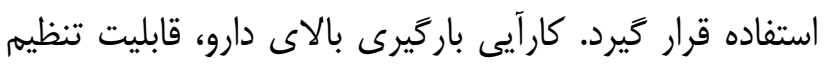

\section{تضاد منافع}

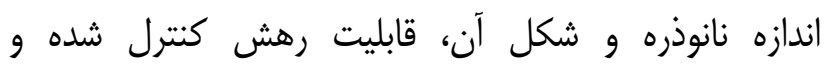

نويسندگان اعلام مىدارند كه هيج گُونه تضاد منافعى در

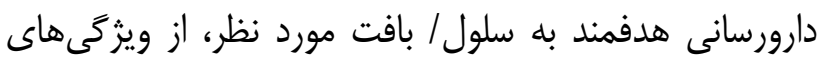

$$
\text { يزوهش حاضر وجود ندارد. }
$$

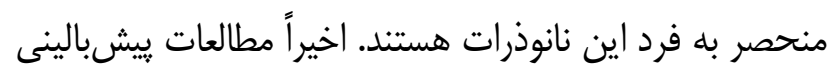

كستردهاى در زمينه زيستساز كارى و سميت نانوذرات سيليكا

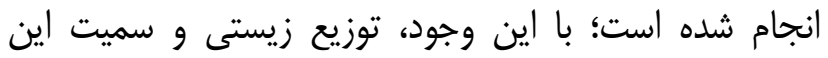

1- Sun T, Zhang YS, Pang B, Hyun DC, Yang M, Xia Y. Engineered nanoparticles for drug delivery in cancer therapy. Angew. Chem Int Ed Engl. 2014; 53(46): 12320-12364. DOI: 10.1002/anie.201403036.

2- Steichen SD, Caldorera-Moore M, Peppas NA. A review of current nanoparticle and targeting moieties for the delivery of cancer therapeutics. Eur J Pharm Sci. 2013; 48(3): 416-27. doi: 10.1016/j.ejps.2012.12.006.

3- Peer D, Karp JM, Hong S, Farokhzad OC, Margalit R, Langer R. Nanocarriers as an emerging platform for cancer therapy. Nature Nanotech. 2007; 2(12): 751-60. doi: 10.1038/nnano.2007.387

4- Hanafi-Bojd MY, Ansari L, Malaekeh-Nikouei B. Codelivery of anticancer drugs and siRNA by mesoporous silica nanoparticles. Ther Deliv. 2016; 7(9): 649-55. doi: 10.4155/tde-2016-0045.

5- Maeda H, Nakamura H, Fang J. The EPR effect for macromolecular drug delivery to solid tumors: Improvement of tumor uptake, lowering of systemic toxicity, and distinct tumor imaging in vivo. Adv Drug Deliv Rev. 2013; 65(1): 71-9. doi: 10.1016/j.addr.2012.10.002.

6- Morales-Cruz M, Delgado Y, Castillo B, Figueroa CM, Molina AM, Torres A, et al. Smart Targeting To Improve Cancer Therapeutics. Drug Des Devel Ther. 2019; 2019: 3753-72. doi: 10.2147/DDDT.S219489.

7- Wicki A, Witzigmann D, Balasubramanian V, Huwyler J. Nanomedicine in cancer therapy: Challenges, opportunities, and clinical applications. J Control Release. 2015; 200: 138-57. doi: 10.1016/j.jconrel.2014.12.030.

8- Majumder J, Taratula O, Minko T. Nanocarrier-based systems for targeted and site specific therapeutic delivery. Adv Drug Deliv Rev. 2019; 144: 57-77. doi: 10.1016/j.addr.2019.07.010

9- Mosallaei N, Jaafari MR, Hanafi-Bojd MY, Golmohammadzadeh S, Malaekeh-Nikouei B. Docetaxel-loaded solid lipid nanoparticles: preparation, characterization, in vitro, and in vivo evaluations. J Pharm Sci. 2013; 102(6): 1994-2004. doi: 10.1002/jps.23522.

10- Croissant JG, Fatieiev Y, Almalik A, Khashab NM. Mesoporous Silica and Organosilica Nanoparticles: Physical Chemistry, Biosafety, Delivery Strategies, and Biomedical Applications. Adv Healthc Mater. 2018; 7(4): 1700831. doi: 10.1002/adhm.201700831

11- Kresge CT, Leonowicz ME, Roth WJ, Vartuli JC, Beck JS. Ordered mesoporous molecular sieves synthesized by a liquid-crystal template mechanism. Nature. 1992; 359(6397): 710-2. doi: 10.1038/359710a0 
12- Jalalian SH, Taghdisi SM, Shahidi Hamedani N, Kalat SAM, Lavaee P, ZandKarimi M, et al. Epirubicin loaded super paramagnetic iron oxide nanoparticle-aptamer bioconjugate for combined colon cancer therapy and imaging in vivo. Eur J Pharm Sci. 2013; 50(2): 191-7. doi: 10.1016/j.ejps.2013.06.015.

13- Lin YS, Hurley KR, Haynes CL. Critical considerations in the biomedical use of mesoporous silica nanoparticles. J Phys Chem Lett. 2012; 3(3): 364-74. doi: 10.1021/jz2013837

14- Hoffmann F, Cornelius M, Morell J, Froba M. Silica-based mesoporous organic-inorganic hybrid materials. Angew Chem Int Ed. 2006; 45(20): 3216-51. doi: 10.1002/anie.200503075

15- Liu Q, Zhang J, Sun W, Xie QR, Xia W, Gu H. Delivering hydrophilic and hydrophobic chemotherapeutics simultaneously by magnetic mesoporous silica nanoparticles to inhibit cancer cells. Int J Nanomedicine. 2012; 7: 999-1013. doi: 10.2147/IJN.S28088.

16- Chen X, Liu Z. Dual responsive mesoporous silica nanoparticles for targeted co-delivery of hydrophobic and hydrophilic anticancer drugs to tumor cells. J Mater Chem B. 2016; 4(25): 4382-8. doi: 10.1039/C6TB00694A.

17- Hanafi-Bojd MY, Ansari L, Mosaffa F, Malaekeh-Nikouei B. The effect of mesoporous silica nanoparticles loaded with epirubicin on drug-resistant cancer cells. Nanomed J. 2017; 4(3): 135-41. doi: 10.22038/nmj.2017.8954.

18- Lewandowski D, Ruszkowski P, Pińska A, Schroeder G, Kurczewska J. SBA-15 Mesoporous Silica Modified with Gallic Acid and Evaluation of Its Cytotoxic Activity. PLOS ONE. 2015; 10(7): e0132541. 10.1371/journal.pone.0132541

19- Sarkar A, Ghosh S, Chowdhury S, Pandey B, Sil PC. Targeted delivery of quercetin loaded mesoporous silica nanoparticles to the breast cancer cells. Biochim Biophys Acta Gen Subj. 2016; 1860(10): 2065-75. doi: 10.1016/j.bbagen.2016.07.001

20- Lin J, Cai Q, Tang Y, Xu Y, Wang Q, Li T, et al. PEGylated Lipid bilayer coated mesoporous silica nanoparticles for co-delivery of paclitaxel and curcumin: Design, characterization and its cytotoxic effect. Int J Pharm. 2018; 536(1): 272-82. doi: 10.1016/j.ijpharm.2017.10.043.

21- Kong ZL, Kuo HP, Johnson A, Wu LC, Chang KLB. Curcumin-Loaded Mesoporous Silica Nanoparticles Markedly Enhanced Cytotoxicity in Hepatocellular Carcinoma Cells. Int J Mol Sci. 2019; 20(12): 2918. doi: 10.3390/ijms20122918.

22- Lv Y, Li J, Chen H, Bai Y, Zhang L. Glycyrrhetinic acid-functionalized mesoporous silica nanoparticles as hepatocellular carcinoma-targeted drug carrier. Int J Nanomedicine. 2017; 12: 4361-70. doi: 10.2147/IJN.S135626.

23- Li N, Wang Z, Zhang Y, Zhang K, Xie J, Liu Y, et al. Curcumin-loaded redox-responsive mesoporous silica nanoparticles for targeted breast cancer therapy. Artif Cells Nanomed Biotechnol. 2018; 46(sup2): 921-35. doi: 10.1080/21691401.2018.1473412.

24- Hanafi-Bojd MY, Jaafari MR, Ramezanian N, Xue M, Amin M, Shahtahmassebi N, et al. Surface functionalized mesoporous silica nanoparticles as an effective carrier for epirubicin delivery to cancer cells. Eur J Pharm Biopharm. 2015; 89: 248-58. doi: 10.1016/j.ejpb.2014.12.009

25- Meng H, Xue M, Xia T, Ji Z, Tarn DY, Zink JI, et al. Use of size and a copolymer design feature to improve the biodistribution and the enhanced permeability and retention effect of doxorubicin-loaded mesoporous silica nanoparticles in a murine xenograft tumor model. ACS Nano. 2011; 5(5): 4131-44. doi: 10.1021/nn200809t

26- Attia MF, Anton N, Wallyn J, Omran Z, Vandamme TF. An overview of active and passive targeting strategies to improve the nanocarriers efficiency to tumour sites. J Pharm Pharmacol. 2019; 71(8): 1185-98. doi: 10.1111/jphp.13098.

27- Wang X, Li S, Shi Y, Chuan X, Li J, Zhong T, et al. The development of site-specific drug delivery nanocarriers based on receptor mediation. J Control Release. 2014; 193: 139-53. doi: 10.1016/j.jconrel.2014.05.028.

28- Arranja AG, Pathak V, Lammers T, Shi Y. Tumor-targeted nanomedicines for cancer theranostics. Pharmacol Res. 2017; 115: 87-95. doi: 10.1016/j.phrs.2016.11.014.

29- Ku SH, Kim K, Choi K, Kim SH, Kwon IC. Tumor-Targeting Multifunctional Nanoparticles for siRNA Delivery: Recent Advances in Cancer Therapy. Adv Healthc Mater. 2014; 3(8): 1182-93. doi: 10.1002/adhm.201300607. 
30- Bhavsar D, Gajjar J, Sawant K. Formulation and development of smart $\mathrm{pH}$ responsive mesoporous silica nanoparticles for breast cancer targeted delivery of anastrozole: In vitro and in vivo characterizations. Microporous Mesoporous Mater. 2019; 279:107-16. doi: 10.1016/j.micromeso.2018.12.026

31- Dosio F, Arpicco S, Stella B, Fattal E. Hyaluronic acid for anticancer drug and nucleic acid delivery. Adv Drug Deliv Rev. 2016; 97: 204-36. doi: 10.1016/j.addr.2015.11.011

32- Huang G, Huang H. Hyaluronic acid-based biopharmaceutical delivery and tumor-targeted drug delivery system. J Control Release. 2018; 278: 122-6. doi: 10.1016/j.jconrel.2018.04.015

33- Palanikumar L, Kim J, Oh JY, Choi H, Park MH, Kim C, et al. Hyaluronic Acid-Modified Polymeric Gatekeepers on Biodegradable Mesoporous Silica Nanoparticles for Targeted Cancer Therapy. ACS Biomater Sci Eng. 2018; 4(5): 1716-22. doi: 10.1021/acsbiomaterials.8b00218

34- Ke Y, Xiang C. Transferrin receptor-targeted HMSN for sorafenib delivery in refractory differentiated thyroid cancer therapy. Int J Nanomedicine. 2018; 13: 8339-54. doi: 10.2147/IJN.S187240

35- Hanafi-Bojd MY, Moosavian Kalat SA, Taghdisi SM, Ansari L, Abnous K, Malaekeh-Nikouei B. MUC1 aptamerconjugated mesoporous silica nanoparticles effectively target breast cancer cells. Drug Dev Ind Pharm. 2018; 44(1): 13-8. doi: 10.1080/03639045.2017.1371734.

36- Ozcan G, Ozpolat B, Coleman RL, Sood AK, Lopez-Berestein G. Preclinical and clinical development of siRNAbased therapeutics. Adv Drug Deliv Rev. 2015; 87: 108-19. doi: 10.1016/j.addr.2015.01.007.

37- John M, Constien R, Akinc A, Goldberg M, Moon YA, Spranger M, et al. Effective RNAi-mediated gene silencing without interruption of the endogenous microRNA pathway. Nature. 2007; 449(7163): 745-7. doi: 10.1038/nature06179.

38- Senapati D, Patra BC, Kar A, Chini DS, Ghosh S, Patra S, et al. Promising approaches of small interfering RNAs (siRNAs) mediated cancer gene therapy. Gene. 2019; 719: 144071. doi: 10.1016/j.gene.2019.144071.

39- Grimm D. Small silencing RNAs: State-of-the-art. Adv Drug Deliv Rev. 2009; 61(9): 672-703. doi: 10.1016/j.addr.2009.05.002.

40- Tan SJ, Kiatwuthinon P, Roh YH, Kahn JS, Luo D. Engineering Nanocarriers for siRNA Delivery. Small. 2011; 7(7): 841-56. doi: 10.1002/smll.201001389.

41- Aigner A. Nonviral in vivo delivery of therapeutic small interfering RNAs. Curr Opin Mol Ther. 2007; 9(4): $345-$ 52.

42- Juliano R, Alam MR, Dixit V, Kang H. Mechanisms and strategies for effective delivery of antisense and siRNA oligonucleotides. Nucleic Acids Res. 2008; 36(12): 4158-71. doi: 10.1093/nar/gkn342

43- Ngamcherdtrakul W, Morry J, Gu S, Castro DJ, Goodyear SM, Sangvanich T, et al. Cationic Polymer Modified Mesoporous Silica Nanoparticles for Targeted siRNA Delivery to HER2+ Breast Cancer. Adv Funct Mater. 2015; 25(18): 2646-59. doi: 10.1002/adfm.201404629

44- Yu M, Niu Y, Yang Y, Hartono SB, Yang J, Huang X, et al. An approach to prepare polyethylenimine functionalized silica-based spheres with small size for siRNA delivery. ACS Appl Mater Interfaces. 2014; 6(18): 15626-31. doi: 10.1021/am503060n.

45- Chen AM, Zhang M, Wei D, Stueber D, Taratula O, Minko T, et al. Co-delivery of doxorubicin and Bcl-2 siRNA by mesoporous silica nanoparticles enhances the efficacy of chemotherapy in multidrug-resistant cancer cells. Small. 2009; 5(23): 2673-7. doi: 10.1002/smll.200900621.

46- Meng H, Liong M, Xia T, Li Z, Ji Z, Zink JI, et al. Engineered design of mesoporous silica nanoparticles to deliver doxorubicin and p-glycoprotein siRNA to overcome drug resistance in a cancer cell line. ACS Nano. 2010; 4(8): 4539-50. doi: 10.1021/nn100690m

47- Hanafi-Bojd MY, Jaafari MR, Ramezanian N, Abnous K, Malaekeh-Nikouei B. Co-delivery of epirubicin and siRNA using functionalized mesoporous silica nanoparticles enhances in vitro and in vivo drug efficacy. Curr Drug Deliv. 2016; 13(7): 1176-82. doi: 10.2174/1567201813666151231094056. 
48- Braun K, Stürzel CM, Biskupek J, Kaiser U, Kirchhoff F, Lindén M. Comparison of different cytotoxicity assays for in vitro evaluation of mesoporous silica nanoparticles. Toxicol In Vitro. 2018; 52: 214-21. doi: 10.1016/j.tiv.2018.06.019.

49- Jafari S, Derakhshankhah H, Alaei L, Fattahi A, Varnamkhasti BS, Saboury AA. Mesoporous silica nanoparticles for therapeutic/diagnostic applications. Biomed Pharmacother. 2019; 109: 1100-11. doi: 10.1016/j.biopha.2018.10.167

50- Sadeghnia HR, Zoljalali N, Hanafi-Bojd MY, Nikoofal-Sahlabadi S, Malaekeh-Nikouei B, Effect of mesoporous silica nanoparticles on cell viability and markers of oxidative stress. Toxicol Mech Methods. 2015, 25(6): 433-439.

51- Croissant JG, Fatieiev Y, Khashab NM. Degradability and Clearance of Silicon, Organosilica, Silsesquioxane, Silica Mixed Oxide, and Mesoporous Silica Nanoparticles. Advanced Materials. 2017; 29(9):1604634. doi: 10.1002/adma.201604634 